\title{
Binding of carbon coated nano-silicon in graphene sheets by wet ball- milling and pyrolysis as high performance anodes for Lithium-ion batteries
}

Wei Sun, Renzong Hu, Miao Zhang, Jiangwen Liu, and Min Zhu*

Guangdong Provincial Key Laboratory of Advanced Energy Storage Materials, South China University of Technology, Guangzhou 510641, China

"Corresponding author. Tel: +86-20-87113924; Fax: +86-20-87111317.

E-mail address: memzhu@ scut.edu.cn

\begin{abstract}
A novel approach has been developed to prepare silicon@carbon/graphene sheets ( $\mathrm{Si} @ \mathrm{C} / \mathrm{G})$ composite with a unique structure, in which carbon coated Si nanoparticles are uniformly dispersed in a matrix of graphene sheets, to enhance the cycleability and electronic conductivity of Si-based anodes for Li-ion batteries. In this study, $\mathrm{Si}$ nanoparticles and expanded graphite (EG) are treated by combining high-energy wet ball-milling in sucrose solution with subsequent pyrolysis treatment to produce this $\mathrm{Si} @ \mathrm{C} / \mathrm{G}$ composite. To achieve better overall electrochemical performance, the carbon content of the composites is also studied systematically. The as-designed $\mathrm{Si}_{30} @ \mathrm{C}_{40} / \mathrm{G}_{30}$ (Si:C:G = 30:40:30, by weight) composite exhibits a high Li-storage capacity of 1259 $\mathrm{mAh} \mathrm{g}^{-1}$ at a current density of $0.2 \mathrm{~A} \mathrm{~g}^{-1}$ in the first cycle. Further, a stable cycleability with 99.1/88.2\% capacity retention from initial reversible charge capacity can be
\end{abstract}


achieved over 100/300 cycles, showing great promise for batteries applications. This good electrochemical performance can be attributed to the uniform coating and binding effect of pyrolytic carbon as well as the network of graphene sheets, which increase the electronic conductivity and $\mathrm{Li}^{+}$diffusion in the composite, and effectively accommodated the volume change of $\mathrm{Si}$ nanoparticles during the $\mathrm{Li}^{+}$alloying and dealloying processes.

Keywords: Lithium ion batteries, Silicon anode, Graphene sheets, Wet ball-milling 


\section{Introduction}

Li-ion batteries (LIBs) have become essential energy storage devices for small electronics as well as electric vehicles due to their high energy densities.[1,2] The increasing demand for higher energy density has driven intense researches in improving LIB performance.[3] Silicon ( $\mathrm{Si}$ ) is an attractive material for use as anode in energy storage devices, since it can provide a high specific capacity that is an order of magnitude higher than that of conventional graphite.[4, 5] Unfortunately, its potential for extensive use in commercial applications has been hindered by severe capacity fading and loss of electrical contact caused by the large volume change, structural crumbling and cracking during repeated charging/discharging, especially cycled at high current rates.[6] In particular, Si has poor electronic conductivity, which can result in large potential polarization and thus greatly hinders the high-rate capability.[7, 8]

Many efforts have been made to increase the capacity retention with battery cycling of Si-based anodes. $\mathrm{Si}-\mathrm{C}$ composites are commonly prepared with $\mathrm{Si}$ nanoparticles dispersed homogeneously into a carbonaceous matrix.[5, 6, 9] In these nanocomposites, the nanosized Si particles help to accommodate the volume change, facilitate more efficient electronic/ionic diffusion and provide more active sites; the carbonaceous matrix maintains the electrical contact of the electrode with the current collector, alleviates the large stress developed during continuous charge/discharge cycling. [10, 11] In recent years, graphene sheets have been demonstrated to be a suitable carbonaceous matrix for $\mathrm{Si}$ nanoparticles, because they have unique physical and chemical properties such as high electronic conductivity, good mechanical flexibility 
and high chemical stability.[12-14] Indeed, conductive and flexible graphene sheets could serve as an interfacial adhesion pathway and mechanical support to prevent capacity fading by keeping good electrical contact between the Si nanoparticles.[15, 16]

However, in the case of Si/graphene composite anodes, two important difficulties remain. Firstly, the Si nanoparticles can easily lose electrical contact with the graphene matrix and then lose capacity during the lithiation and delithiation processes, caused by the repeated large volume expansion/contraction. Secondly, Si nanoparticles that are highly dispersed in the graphene sheets, are difficult to prepare by simply mechanical blending; this is an important consideration to achieve good performance.[17] Furthermore, the graphene sheets are usually, produced by mechanical peeling of graphite[18, 19], chemical vapor deposition (CVD)[20], and chemical or thermal reduction of graphene oxide[21-23]. However, mechanical peeling and CVD are often too expensive and not suitable for mass production. The normally used preparation methods for Si/graphene composites based on graphite oxide require harsh conditions such as strong oxidizing and reducing reagents, high temperature and time-consuming preparation processes.[18, 24, 25] Besides, the graphene prepared from graphene oxide still retains many residual oxygen functional groups and structural defects which lower the electronic conductivity.[17]

Recently, a double protection strategy to improve the electrode performance of $\mathrm{Si}$ through the use of carbon coating and graphene has been developed.[26-29] For example, Feng et al. designed a Si-rGO-C composite with Si nanoparticles well wrapped by an $\mathrm{rGO} /$ carbon hybrid, leading to an improved cycling performance 
compared to Si-rGO composite.[26] Li et al. developed a straightforward approach to simultaneously realize the carbon coating of Si nanoparticles and the good dispersion of graphene sheets, thus achieving the double goals of buffering the volume changes and improving the electrical conductivity.[27] In this work, to simplify the aforementioned complicated fabrication process of graphene and carbon coating, we have adopted a new method combining high energy wet ball-milling with pyrolysis treatment for the large-scale production of $\mathrm{Si} @$ carbon/graphene $(\mathrm{Si} @ \mathrm{C} / \mathrm{G})$ composite (Fig. 1). During the wet ball-milling process, the graphene sheets were efficiently exfoliated from the expanded graphite (EG) by the shear force provided by the zirconia balls in sucrose solution. Meanwhile, the Si nanoparticles and graphene sheets were uniformly dispersed in the sucrose solution by the high-speed motor-driven grinder. Next, the Si@C/G composite was obtained by drying and in-situ carbonization of the sucrose coated on the surface of the Si nanoparticles by pyrolysis. This unique structure was expected to provide superior $\mathrm{Li}^{+}$storage because it should improve the electronic conductivity and $\mathrm{Li}^{+}$diffusion as well as provide an elastic buffer to accommodate the volume variation of the $\mathrm{Si}$ nanoparticles during the $\mathrm{Li}^{+}$alloying and dealloying processes. We found that the as-obtained $\mathrm{Si} @ \mathrm{C} / \mathrm{G}$ composite exhibited remarkably enhanced cycling and rate performance compared with bare Si nanoparticles and $\mathrm{Si} / \mathrm{G}$ control samples as anode for Li-ion batteries. 


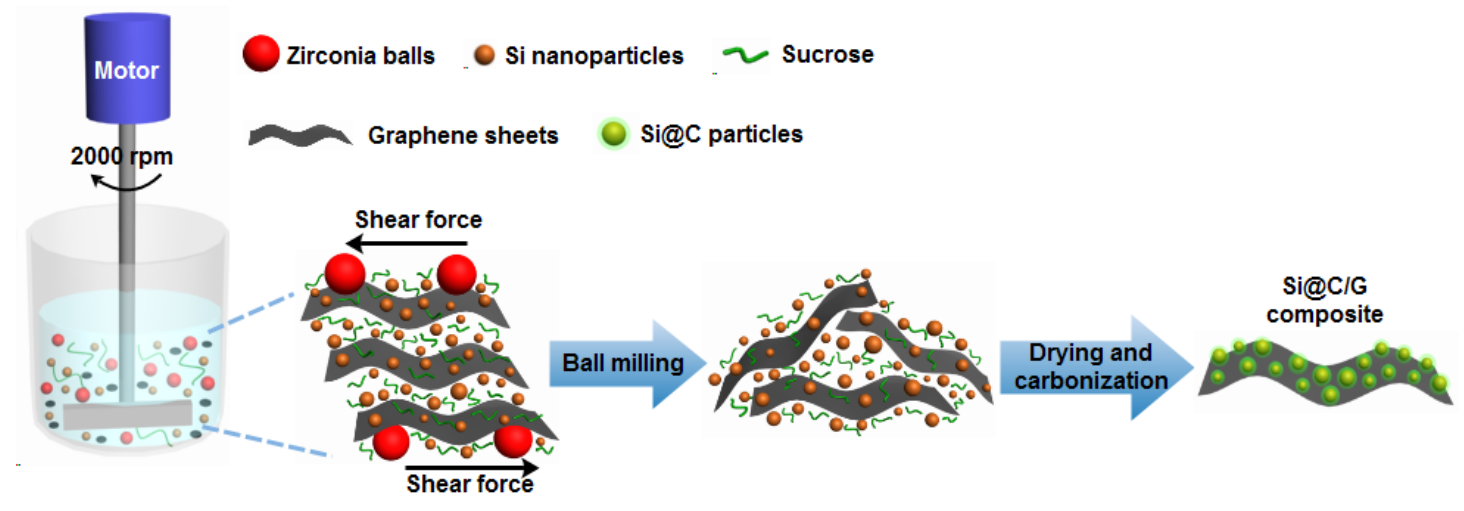

Fig. 1 Schematics illustration of the synthesis of the $\mathrm{Si} @ \mathrm{C} / \mathrm{G}$ composites through combining highenergy wet ball milling and pyrolysis treatment.

\section{Experimental}

\subsection{Material preparation}

Expandable graphite (99.9\% purity, 100 mesh, Qingdao Xinghua Graphite Products Co., Ltd.) was quickly inserted into a tube furnace preheated to $1000^{\circ} \mathrm{C}$ and held in the furnace for 60s under an Ar atmosphere to obtain worm-like EG.[30] Si nanoparticles (99.9\% purity, 50-100 nm in size, Shanghai ST-nano Science and Technology Co., Ltd), sucrose (99.9\% purity, Sinopharm Chemical Reagent Co., Ltd, China) and the asobtained EG were used as raw materials. To investigate the effect of carbon content on the anode performance, an optimized mass ratio (1:1) of Si to EG powder was mixed in a water/ethanol $(1 / 1, \mathrm{v} / \mathrm{v})$ solution with different amounts of sucrose added. After 5 min ultrasonication, the obtained suspension was ground by a ball mill in a zirconia vial with zirconia balls $(0.8 \mathrm{~mm})$ to form a homogeneous suspension. Detail of the wet ballmilling have been described previously.[31, 32] The mass ratio of zirconia balls to the whole raw material was maintained at 20:1 and the mixture was milled for $2 \mathrm{~h}$ at 2000 
$\mathrm{rpm}$. Subsequently, the suspension was dried at $80{ }^{\circ} \mathrm{C}$ for $5 \mathrm{~h}$ to form a dry precursor, which was then subjected to pyrolytic carbonizing treatment in a tube furnace for $2 \mathrm{~h}$ under an $\mathrm{Ar}$ atmosphere with a heating rate of $10^{\circ} \mathrm{C} \min ^{-1}$ to a final temperature of $600{ }^{\circ} \mathrm{C}$. Finally, after naturally cooling to room temperature within the furnace, the final product was ground and sifted to approximately 300 mesh for use as active material to measure its electrochemical properties. Specifically, the mass ratio of Si:carbon:EG (Si:C:G) in the composite was varied systematically (based on the carbon yield of sucrose of about 40\%[33]), including ratios of 20:60:20 (labeled as $\mathrm{Si}_{20} @ \mathrm{C}_{60} / \mathrm{G}_{20}$ ), 30:40:30 (labeled as $\mathrm{Si}_{30} @ \mathrm{C}_{40} / \mathrm{G}_{30}$ ), and 40:20:40 (labeled as $\mathrm{Si}_{40} @ \mathrm{C}_{20} / \mathrm{G}_{40}$ ). For comparison, a control sample of $\mathrm{Si} @ \mathrm{C}(\mathrm{Si}: \mathrm{C}=50: 50$, by weight $)$ and $\mathrm{Si} / \mathrm{G}(\mathrm{Si}: \mathrm{EG}=50: 50$, by weight) composite was prepared using the same process without the addition of expanded graphite and sucrose, respectively. These control samples and pristine Si nanoparticles were also tested as electrodes for comparison.

\subsection{Material characterization}

Materials were characterized using X-ray diffraction (XRD, Rigaku MiniFlex 600) with $\mathrm{Cu}-\mathrm{K}_{\alpha}$ radiation, laser Raman spectrometer (Raman, Horiba) with $632.81 \mathrm{~nm}$ laser, scanning electron microscopy (SEM, Carl Zeiss Supra 40), and transmission electron microscopy (TEM, JEOL JEM-2100) operating at $200 \mathrm{kV}$. For TEM observations, the sample was prepared by dispersion of the as-prepared powders on $\mathrm{Cu}$ grids. Thermal gravimetric analysis (TGA) was carried out under an oxygen atmosphere on a TG209F3 (NETZSCH) with heating rate of $10{ }^{\circ} \mathrm{C} \mathrm{min}^{-1}$ from 35 to $1000^{\circ} \mathrm{C}$.

\subsection{Electrochemical measurements}


The electrochemical performance of the samples was investigated using CR2016 coin-type cells assembled in an argon-filled glove box. The working electrode consisted of $80 \mathrm{wt} \%$ active material, $10 \mathrm{wt} \%$ conductivity agent (Super-P), and $10 \mathrm{wt} \%$ carboxymethyl cellulose sodium salt dissolved in distilled water as a binder. The amount of active material loaded on the electrodes was $1.1 \sim 1.3 \mathrm{mg} \mathrm{cm}^{-2}$. Lithium metal foils were used as counter and reference electrodes in the half cells. The electrodes were separated by Teklon ${ }^{@}$ Gold LP separators. The electrolyte was $\mathrm{LiPF}_{6}(1 \mathrm{M})$ in a mixture of ethylene carbonate (EC)/diethyl carbonate (DEC)/ethyl methyl carbonate (EMC) (1:1:1 v:v:v) (Shanshan Tech Co., Ltd).

Galvanostatic charge and discharge tests of the cells were carried out using CT2001A (LAND, China) battery testers. These tests were conducted between 0.01 and $1.5 \mathrm{~V}$ (versus $\mathrm{Li} / \mathrm{Li}^{+}$) at various current densities. The current densities and capacities were based on the weight of active material without conductivity agent and binder. Cyclic voltammograms $(\mathrm{CV})$ were recorded with a Gamry electrochemical system between 0 and $2.0 \mathrm{~V}$ (versus $\mathrm{Li} / \mathrm{Li}^{+}$) at a scanning rate of $0.3 \mathrm{mVs}^{-1}$. Impedance spectra were measured out by applying a $5 \mathrm{mV}$ amplitude signal range from $1 \mathrm{MHz}$ to $0.1 \mathrm{~Hz}$. All electrochemical tests were carried out at ambient temperature.

\section{Results and discussion}



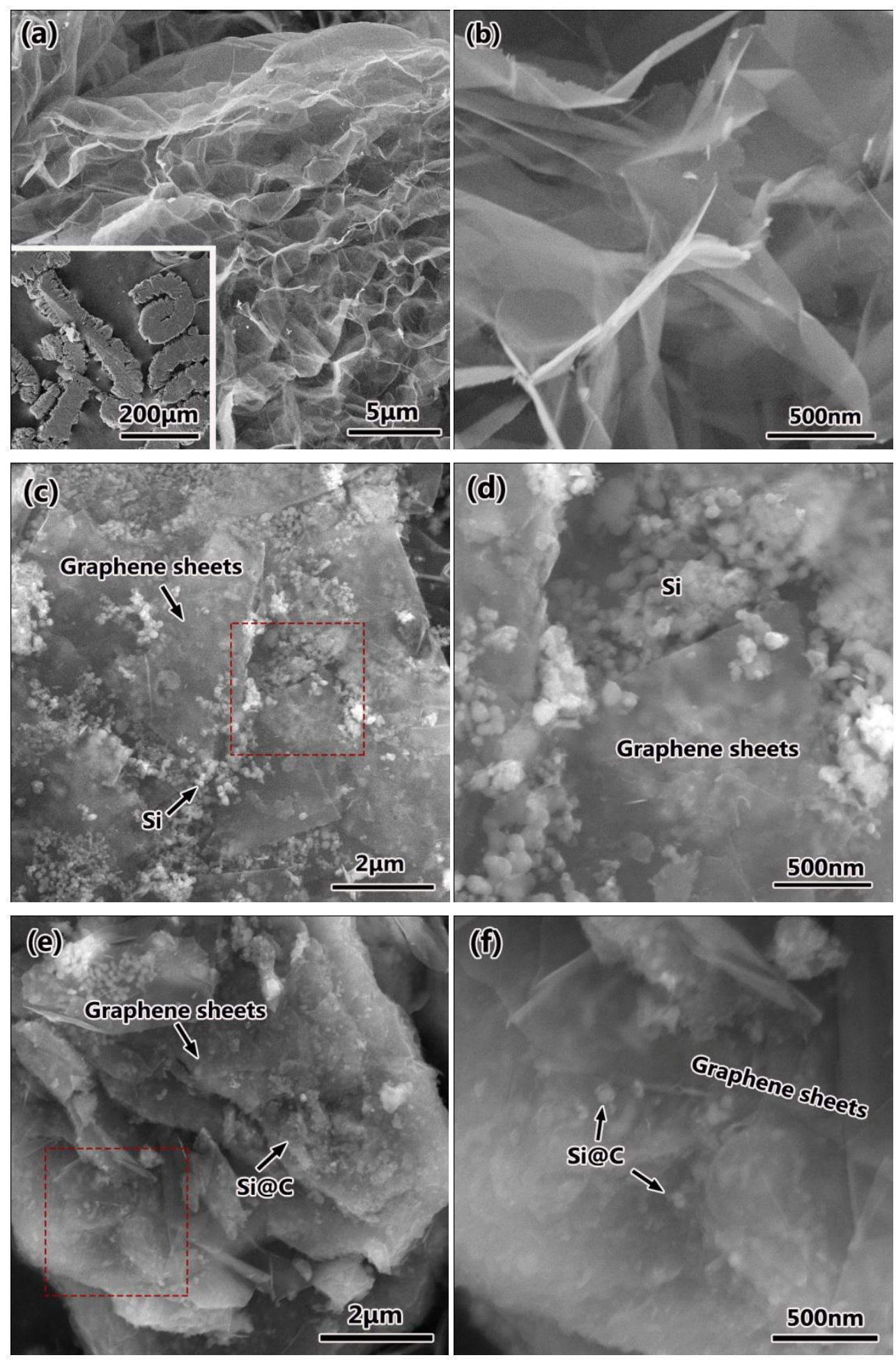

Fig. 2 SEM images of (a, b) EG, (c, d) Si/G composite, and (e, f) $\mathrm{Si}_{30} @ \mathrm{C}_{40} / \mathrm{G}_{30}$ composite at different magnifications. 
According to previous studies, the high temperature $\left(1000{ }^{\circ} \mathrm{C}\right)$ could cause rapid decomposition of the intercalating compounds and then lead to a dramatic increase in the dimension perpendicular to the graphene plane in expandable graphite as well as the formation of expanded graphite (EG).[30, 34, 35] The obtained EG has a loose structure consisting of graphene sheets with a size of several dozens of micrometers (Fig. 2a). The typical worm-like structure of EG can be clearly seen in the lower magnification image presented in the inset of Fig. 2a. At a higher magnification (Fig. 2b), many translucent and wrinkled graphene layers and abundant pores can be observed on the surface of the EG, showing that the pores in the EG are likely to be filled with Si nanoparticles; this is an useful characteristic, to be exploited for the preparation of a composite with Si nanoparticles dispersed inside among the graphene sheets by mechanical mixing. Notably, when the EG and Si nanoparticles were milled in the water/ethanol solution during high-energy wet ball-milling, the large graphene sheets could be efficiently exfoliated from the EG by the shear force provided by the zirconia balls and Si nanoparticles. It is noted that a clear difference can be observed between $\mathrm{Si} / \mathrm{G}$ control sample and $\mathrm{Si}_{30} @ \mathrm{C}_{40} / \mathrm{G}_{30}$ composites, which were synthesized from Si nanoparticles and EG by high energy wet ball-milling in water/ethanol solution without and with the addition of sucrose, respectively. In the $\mathrm{Si} / \mathrm{G}$ composite control sample, the Si nanoparticles are spherical on the nanometer scale, while the graphene sheets exfoliated from the EG are of micrometer size (Fig.2 c). The high-magnification SEM image (Fig. $2 \mathrm{~d}$ ) shows that most of the Si nanoparticles are agglomerated and are in loose contact with the graphene sheets. For the $\mathrm{Si}_{30} @ \mathrm{C}_{40} / \mathrm{G}_{30}$ composite sample 
(Fig. 2 e), the Si nanoparticles are well coated by the carbon derived from the sucrose (noted as Si@C particles) and embedded in graphene sheets. At a higher magnification (Fig.2 f), most of the Si@C particles are entirely covered by the transparent graphene sheets. These results provide good evidence that the majority of those Si nanoparticles were coated by carbon and bound to graphene sheets, which could form electrically conductive networks and greatly improve the electrical conductivity of the whole composite electrode. In addition, the carbon coating and graphene sheets should provide a tolerance for the expansion of $\mathrm{Si}$ and prevent the Si nanoparticle from peeling from graphene during the cycling.

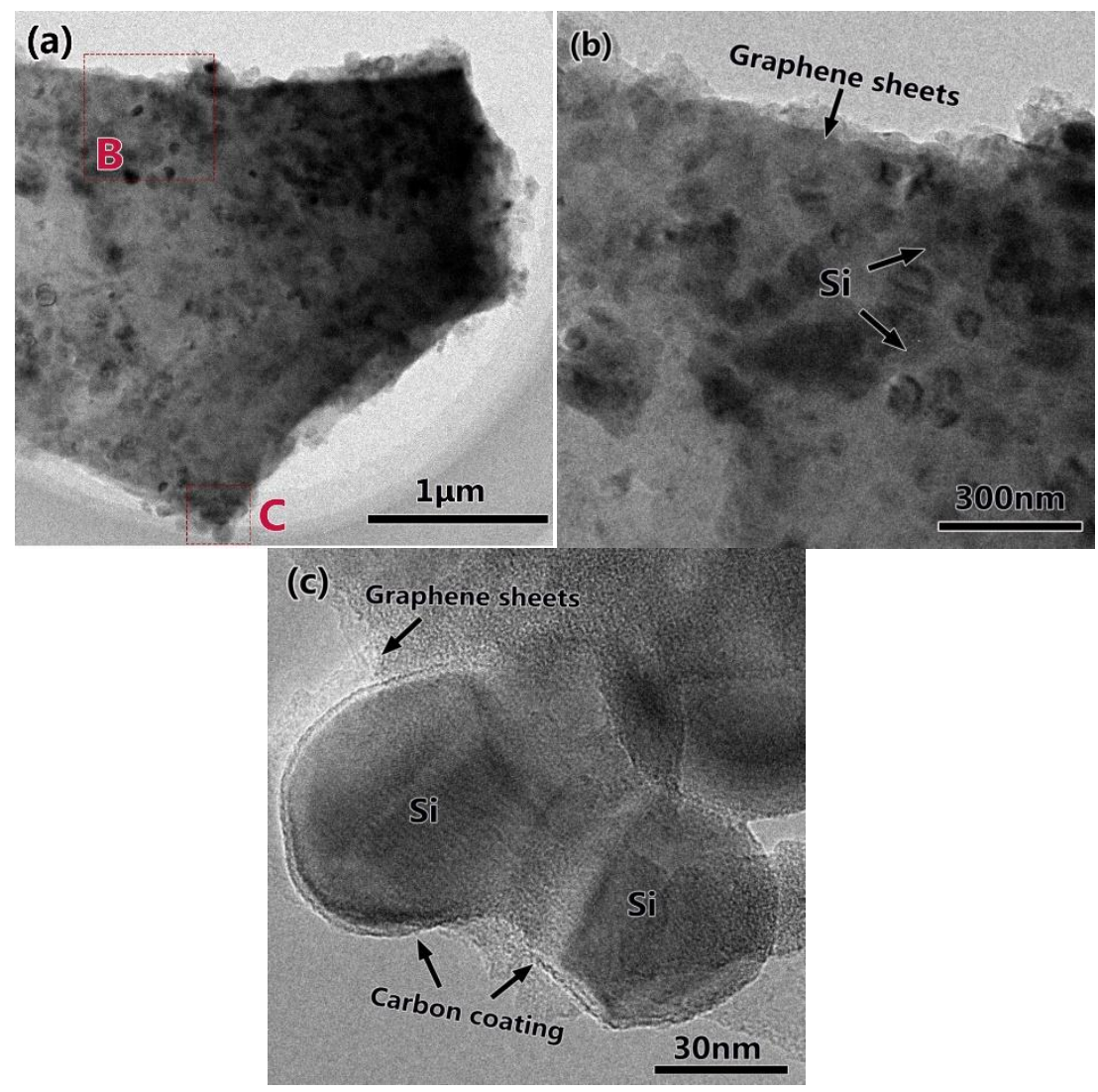

Fig. 3 (a) TEM images of $\mathrm{Si}_{30} @ \mathrm{C}_{40} / \mathrm{G}_{30}$ composite, (b, c) detailed morphology of the square area in (b). 
Transmission electron microscopy (TEM) was carried out to investigate the microstructure of the $\mathrm{Si}_{30} @ \mathrm{C}_{40} / \mathrm{G}_{30}$ composite in more detail. In this typical structure of the $\mathrm{Si}_{30} @ \mathrm{C}_{40} / \mathrm{G}_{30}$ composite (Fig. 3a), the Si nanoparticles were uniformly dispersed and covered by the thin microsized graphene sheets to form secondary granules size of several micrometers. This characteristic structure was further confirmed by the magnified image (Fig. 3b) of zone B enclosed in the dotted square in Fig. 3a. In addition, the detailed morphology (Fig. 3c) of zone C in Fig. 3a revealed that the carbon coated the Si nanoparticles and acted as a bridge connecting the Si nanoparticles and graphene sheets matrix. In this way, the $\mathrm{Si} @ \mathrm{C}$ particles (having a low aggregation) were firmly attached to the networks consisting of thin graphene sheets, which resulted in improving the structural stability and electrical conductivity of the whole electrode. 

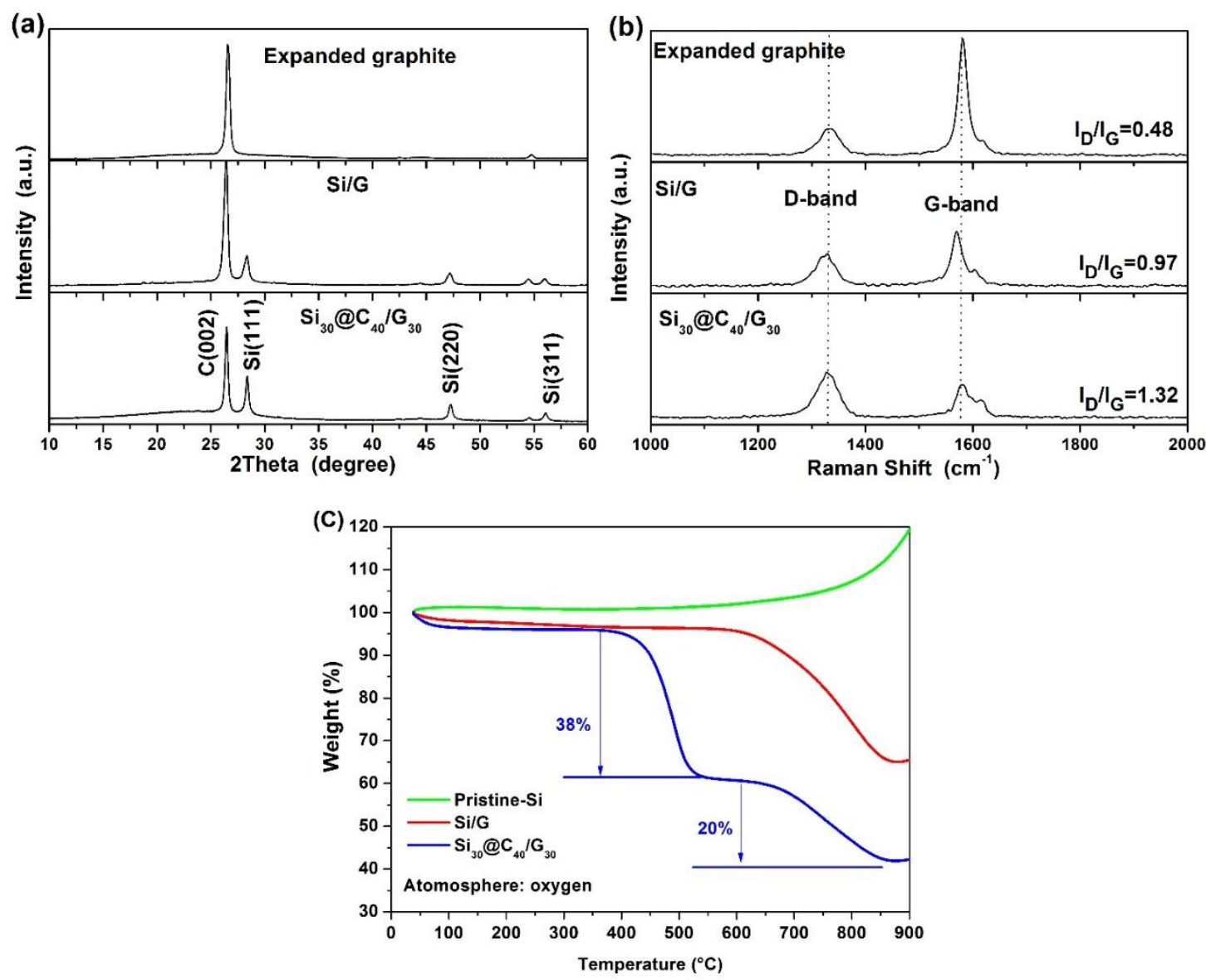

Fig. 4 (a) XRD patterns and (b) Raman spectra of the EG, $\mathrm{Si} / \mathrm{G}$ and $\mathrm{Si}_{30} @ \mathrm{C}_{40} / \mathrm{G}_{30}$ composites. (c)

Thermal gravimetric analysis (TGA) curves of pristine $\mathrm{Si}, \mathrm{Si} / \mathrm{G}$ and $\mathrm{Si}_{30} @ \mathrm{C}_{40} / \mathrm{G}_{30}$ composites under an oxygen atmosphere at a heating rate of $10^{\circ} \mathrm{C} \mathrm{min}^{-1}$.

XRD experiments were carried out to clarify the as-obtained material structure (Fig. 4a). In the XRD pattern of the as-obtained $\mathrm{Si}_{30} @ \mathrm{C}_{40} / \mathrm{G}_{30}$ composite, the main diffraction peaks at $28.6^{\circ}, 47.4^{\circ}$, and $56.3^{\circ}$ can be indexed as the (111), (220) and (311) planes of Si crystallites (JCPDS No. 27-1402), respectively. The peak at $26.5^{\circ}$ is the main characteristic of the (002) plane of the graphite layer, which corresponds to the graphene sheets exfoliated from the EG during the high-energy wet ball-milling process. Compared with the $\mathrm{Si} / \mathrm{G}$ composite, a broad hump appearing around $24^{\circ}$ can be 
observed in the $\mathrm{Si}_{30} @ \mathrm{C}_{40} / \mathrm{G}_{30}$ composite, indicating the amorphous carbon derived from the sucrose in the pyrolysis process.

Raman spectra were measured to further evaluate the structure of carbon in the EG, $\mathrm{Si} / \mathrm{G}$ and $\mathrm{Si}_{30} @ \mathrm{C}_{40} / \mathrm{G}_{30}$ composites (Fig. 4b). The D band can be assigned to disordered carbon, edge and other defects, and the $\mathrm{G}$ band is assigned to the planar sp2-hybridized carbon.[36] The relative intensity ratio of the D and $\mathrm{G}$ bands is known to depend on the structural characteristics of carbon. This ratio can give information about the perfection of the graphite layer structure, reflecting the properties of the edge plane or boundary of the graphite crystal faces.[37] For example, the Raman spectrum of EG exhibits a D band and $\mathrm{G}$ band around 1342 and $1581 \mathrm{~cm}^{-1}$, respectively, with an $\mathrm{I}_{\mathrm{D}} / \mathrm{I}_{\mathrm{G}}$ ratio of 0.48 . After high-energy wet ball-milling with Si nanoparticles, the intensity of the D band increased and the $\mathrm{G}$ band decreased to an $\mathrm{I}_{\mathrm{D}} / \mathrm{I}_{\mathrm{G}}$ ratio of 0.97 , as shown in the Raman spectrum of the $\mathrm{Si} / \mathrm{G}$ composite. This result shows that the layered structure of EG was exfoliated and thinned, and more edges and defects were induced by the wet ballmilling. For the $\mathrm{Si}_{30} @ \mathrm{C}_{40} / \mathrm{G}_{30}$ composite, due to the disordered carbon introduced by the pyrolysis of sucrose, the $\mathrm{I}_{\mathrm{D}} / \mathrm{I}_{\mathrm{G}}$ ratio further increased to $1.32 .[36-38]$

The thermal properties and compositions of these samples were determined by thermal gravimetric analysis (TGA) under an oxygen atmosphere at a heating rate of $10^{\circ} \mathrm{C} \mathrm{min}^{-1}$. When heated in oxygen, the amorphous carbon and graphene sheets in the $\mathrm{Si}_{30} @ \mathrm{C}_{40} / \mathrm{G}_{30}$ composite were combusted and released gas (constituting a weight loss), while the $\mathrm{Si}$ in the composite was oxidized with formation of $\mathrm{SiO}_{2}$ (weight gain). The pristine Si nanoparticles were stable against oxidation up to $600{ }^{\circ} \mathrm{C}$, and $\sim 20 \%$ increase 
in mass was observed at $900{ }^{\circ} \mathrm{C}$ (Fig. 4c). During TGA of the Si/G composite, the weight loss occurred between 600 and $850{ }^{\circ} \mathrm{C}$, indicating that the oxidation and decomposition of the graphene sheets were in this temperature range. Compared with the $\mathrm{Si} / \mathrm{G}$ sample, the $\mathrm{Si}_{30} @ \mathrm{C}_{40} / \mathrm{G}_{30}$ composite showed a unique characteristic weight loss between 400 and $550{ }^{\circ} \mathrm{C}$, which can be ascribed to the complete combustion of pyrolyzed carbon. Calculated from the TGA curve, the weight percentage of pyrolyzed carbon in the $\mathrm{Si}_{30} @ \mathrm{C}_{40} / \mathrm{G}_{30}$ composite was 38\%; considering the small weight gain from the oxidation of $\mathrm{Si}$ over this temperature range, this result is consistent with our designed composition of $\mathrm{Si}_{30} @ \mathrm{C}_{40} / \mathrm{G}_{30}$ (40 wt \% carbon in the composite). 

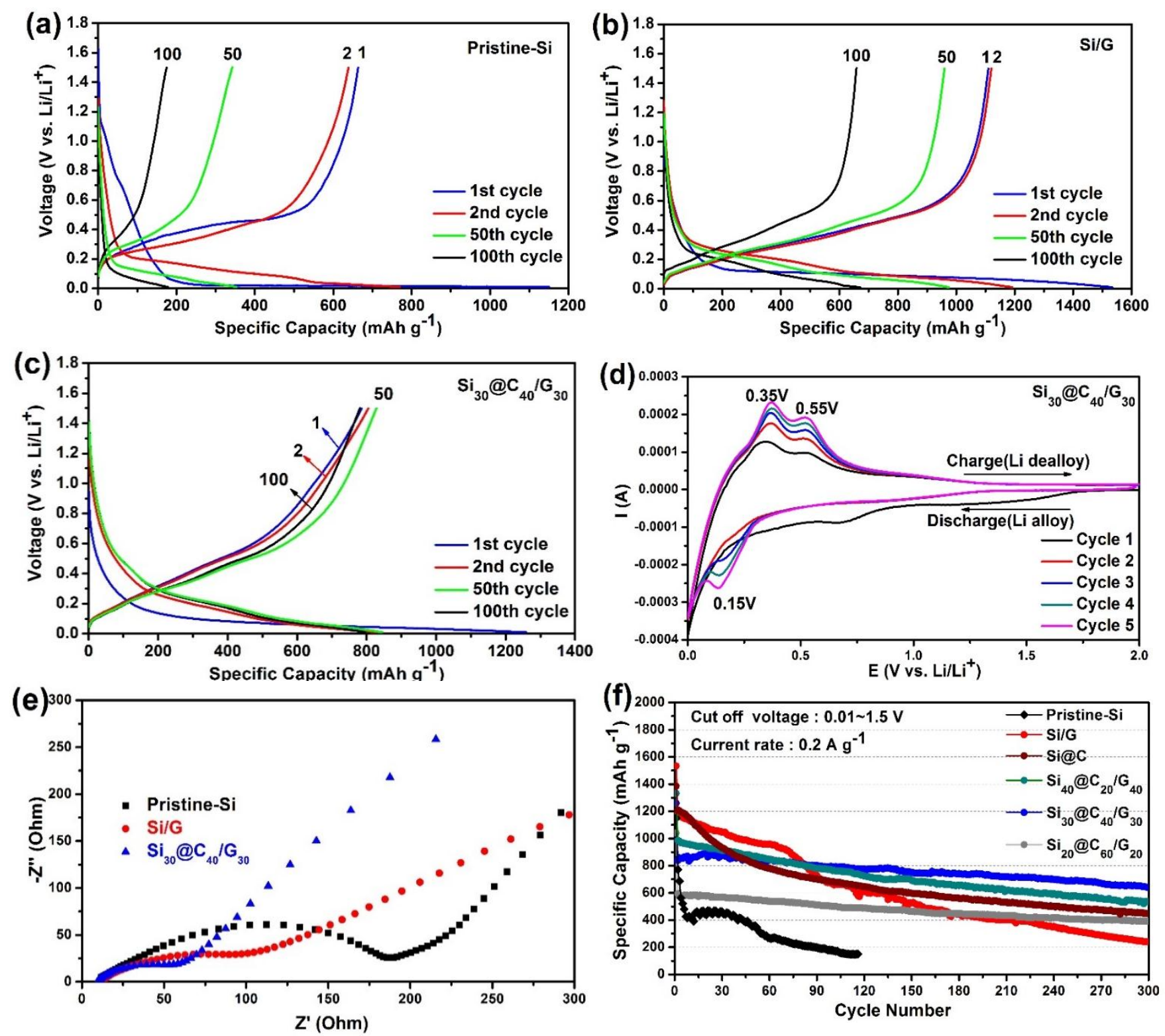

Fig. 5 Voltage profiles of the (a) pristine $\mathrm{Si}$, (b) Si/G and (c) $\mathrm{Si}_{30} @ \mathrm{C}_{40} / \mathrm{G}_{30}$ composites for the first, second $50^{\text {th }}$ and $100^{\text {th }}$ cycle at a current density of $0.2 \mathrm{~A} \mathrm{~g}^{-1}$. (d) Cyclic voltammograms $(\mathrm{CV})$ of the $\mathrm{Si}_{30} @ \mathrm{C}_{40} / \mathrm{G}_{30}$ composite from 0.01 to $2.0 \mathrm{~V}$ at a scanning rate of $0.3 \mathrm{mV} \mathrm{s}^{-1}$. (e) Nyquist plots of the pristine $\mathrm{Si}, \mathrm{Si} / \mathrm{G}$ and $\mathrm{Si}_{30} @ \mathrm{C}_{40} / \mathrm{G}_{30}$ composites. (f) Cycling performance of the $\mathrm{Si} @ \mathrm{C} / \mathrm{G}$ composites with different compositions, and the pristine $\mathrm{Si}, \mathrm{Si} / \mathrm{G}, \mathrm{Si} @ \mathrm{C}$ were presented for comparsion.

The voltage profiles of the pristine-Si, Si/G and $\mathrm{Si}_{30} @ \mathrm{C}_{40} / \mathrm{G}_{30}$ composites for first, 
second, $50^{\text {th }}$ and $100^{\text {th }}$ cycle at a current density of $0.2 \mathrm{~A} \mathrm{~g}^{-1}$ are shown in Fig. 5 a, b and c, respectively. The first discharge/charge capacities, the initial Coulombic efficiency, and capacity retention at the $100^{\text {th }} / 300^{\text {th }}$ cycle of these samples are also listed in Table 1. In the first cycle, the pristine Si electrode shows a discharge capacity of $1151 \mathrm{mAh}$ $\mathrm{g}^{-1}$ with a long plateau below $0.1 \mathrm{~V}$, corresponding to typical $\mathrm{Li}-\mathrm{Si}$ alloying reaction (Fig. 5 a). And the discharge capacity rapidly decreased to 772 and $348 \mathrm{mAh} \mathrm{g}^{-1}$ in the second and $50^{\text {th }}$ cycle. After 100 cycles, this characteristic plateau disappeared with a dramatic decrease in discharge/charge capacity. This result presumably is due to the large volume expansion of $\mathrm{Si}$ and the resulting in loss of contact with the current collector, which means that the $\mathrm{Si}$ cannot react with $\mathrm{Li}^{+}$and contribute to the capacity after 100 cycles. For the control sample of Si/G (Fig. 5b), the discharge capacity of first and second cycle were as high as $1533 \mathrm{mAh} \mathrm{g}^{-1}$ and $1193 \mathrm{mAh} \mathrm{g}^{-1}$, respectively. However, a significant change in voltage profile and fade in reversible charge capacity were observed from second to $50^{\text {th }}$ and $100^{\text {th }}$ cycle. Meanwhile, a capacity of only 665 $\mathrm{mAh} \mathrm{g}^{-1}$ was retained after 100 cycles, corresponding to a poor capacity retention of only $59.9 \%$. As shown in the Fig. 5 c, the $\mathrm{Si}_{30} @ \mathrm{C}_{40} / \mathrm{G}_{30}$ composite also suffered from a relatively high irreversible capacity, which was not only caused by the inevitable formation of SEI layer on silicon particles, but also may be ascribed to the high surface area of the graphene sheets. Remarkably, the voltage profile of second, $50^{\text {th }}$ and $100^{\text {th }}$ cycle are almost overlapped for the $\mathrm{Si}_{30} @ \mathrm{C}_{40} / \mathrm{G}_{30}$ composite, indicating the good reversible electrochemical reaction between lithium ion and $\mathrm{Si}_{30} @ \mathrm{C}_{40} / \mathrm{G}_{30}$ electrode in the subsequent cycles. 
The electrochemical performance of the $\mathrm{Si}_{30} @ \mathrm{C}_{40} / \mathrm{G}_{30}$ composite used as an anode was also investigated by cyclic voltammogrammetry. In the first cathodic scan (Fig. 5c), one broad reduction peak located at approximately $0.7 \mathrm{~V}$ versus $\mathrm{Li} / \mathrm{Li}^{+}$can be attributed to the irreversible reduction of electrolyte and the formation of a solid electrolyte interphase (SEI) film on the anode, which disappeared during the subsequent cycles. The other two cathodic peaks at approximately $0.15 \mathrm{~V}$ and below $0.1 \mathrm{~V}$ are attributed to Li-Si alloy formation. The remaining anode peaks at approximately 0.35 and $0.55 \mathrm{~V}$ are therefore related to the decomposition of the $\mathrm{Li}-\mathrm{Si}$ phases. It seems reasonable to conclude that the overall lithium storage of the $\mathrm{Si}_{30} @ \mathrm{C}_{40} / \mathrm{G}_{30}$ composite is mainly provided by Si nanoparticles.

In the Nyquist plots of pristine $\mathrm{Si}, \mathrm{Si} / \mathrm{G}$ and $\mathrm{Si}_{30} @ \mathrm{C}_{40} / \mathrm{G}_{30}$ composites after the first charge-discharge cycle at $1.5 \mathrm{~V}$ (Fig. 5d), the semicircle in the medium-frequency region can be attributed to charge-transfer resistance (Rct), and the inclined line in the low frequency range corresponds to lithium diffusion in the electrodes.[39] The pristine Si anode clearly has the largest Rct among the three samples. Remarkably, the Rct of the $\mathrm{Si} / \mathrm{G}$ electrode is greatly reduced, indicating that the graphene sheets are beneficial to the electron transfer. Apparently, the diameter of the semicircle for the $\mathrm{Si}_{30} @ \mathrm{C}_{40} / \mathrm{G}_{30}$ composite electrode is much smaller than that of the pristine $\mathrm{Si}$ and $\mathrm{Si} / \mathrm{G}$ electrode. This decrease in Rct can be explained by the likelihood that the carbon layer improves the electron/ion transfer during electrochemical reaction; the wrapped graphene sheets provide further conductivity improvement.

Finally, the long-term cycle performance of pristine Si, Si/G, Si@C, and Si@C/G 
composites with different compositions were evaluated by galvanostatic charge/discharge measurements. The pristine-Si electrode exhibits abrupt capacity decay at a current density of $0.2 \mathrm{~A} \mathrm{~g}^{-1}$ within less than 10 cycles (Fig. 5e). For the control sample of $\mathrm{Si} / \mathrm{G}$, though the initial discharge capacity was as high as $1533 \mathrm{mAh}$ $\mathrm{g}^{-1}$, a capacity of only $665 \mathrm{mAh} \mathrm{g}^{-1}$ was retained after 100 cycles, corresponding to capacity retention of only $59.9 \%$. This fade in capacity seemingly occurs because the exposed Si nanoparticles aggregate and easily lose contact with the graphene sheets matrix during the repeated charge/discharge process. For the control Si@C sample, although the carbon coating could enhance the cycling performance of the bare $\mathrm{Si}$ nanoparticles, the specific capacity of the Si@C decreased gradually form 1385 mAh $\mathrm{g}^{-1}$ at the first cycle to $447 \mathrm{mAh} \mathrm{g}^{-1}$ after 300 cycles. Importantly, with the in-situ introduction of the pyrolyzed carbon, all the $\mathrm{Si} @ \mathrm{C} / \mathrm{G}$ composites show improved cycling performance over the pristine Si , Si@C, and Si/G composite. The pyrolyzed carbon not only improves the electrical conductivity of Si nanoparticles between each other as well as with the graphene sheet matrix, but also buffers the volume change of Si during lithium insertion and extraction, thus improving the cycling stability of all these Si@C/G composites. Therefore, we concluded that the homogeneous dispersion of Si nanoparticles in the graphene sheets matrix as well as the effective connecting and coating of the carbon are the key factors contributing to the superior cycle performance of the composite.

The first discharge/charge capacities, the initial Coulombic efficiency, and capacity retention at the $100^{\text {th }} / 300^{\text {th }}$ cycle of the $\mathrm{Si} @ \mathrm{C} / \mathrm{G}$ composites with different compositions 
are also listed in Table 1. The discharge/charge capacities of Si@C/G composites in the first cycle decrease with increasing carbon content, resulting from the decrease in the amount of the high-capacity $\mathrm{Si}$ nanoparticles. In addition, the initial Coulombic efficiencies of the composites decrease with increasing carbon contents, resulting from carbon generating high irreversible capacity by the formation of the SEI layer. However, the capacity and capacity retention after 300 cycles of the $\mathrm{Si} @ \mathrm{C} / \mathrm{G}$ composites first increase and then decrease with the increasing carbon content, reaching a maximum value of $645 \mathrm{mAh} \mathrm{g}^{-1}$ and $82.1 \%$ when the carbon content is $30 \mathrm{wt} . \%$. In other words, the $\mathrm{Si}_{30} @ \mathrm{C}_{40} / \mathrm{G}_{30}$ sample shows the best cycleability and overall cycling performance among these three $\mathrm{Si} @ \mathrm{C} / \mathrm{G}$ composites. Besides, some available representative results of the $\mathrm{Si}-\mathrm{C}$ based anodes reported by other researchers were also presented in Table 1 for comparison.[22, 27, 29, 40, 41] Due to the low Si content, the specific capacity of the optimized Si30@C40/G30 composite sample is relatively lower than the Si/C composite materials reported by other researchers. However, the capacity retention of the Si30@C40/G30 composite sample is comparable to these counterpart. In addition, the initial Coulombic efficiency of the $\mathrm{Si}_{30} @ \mathrm{C}_{40} / \mathrm{G}_{30}$ sample was relatively low with a figure of $62.4 \%$, which could be reduced by a prelithiation treatment and will be reported in our future work. 

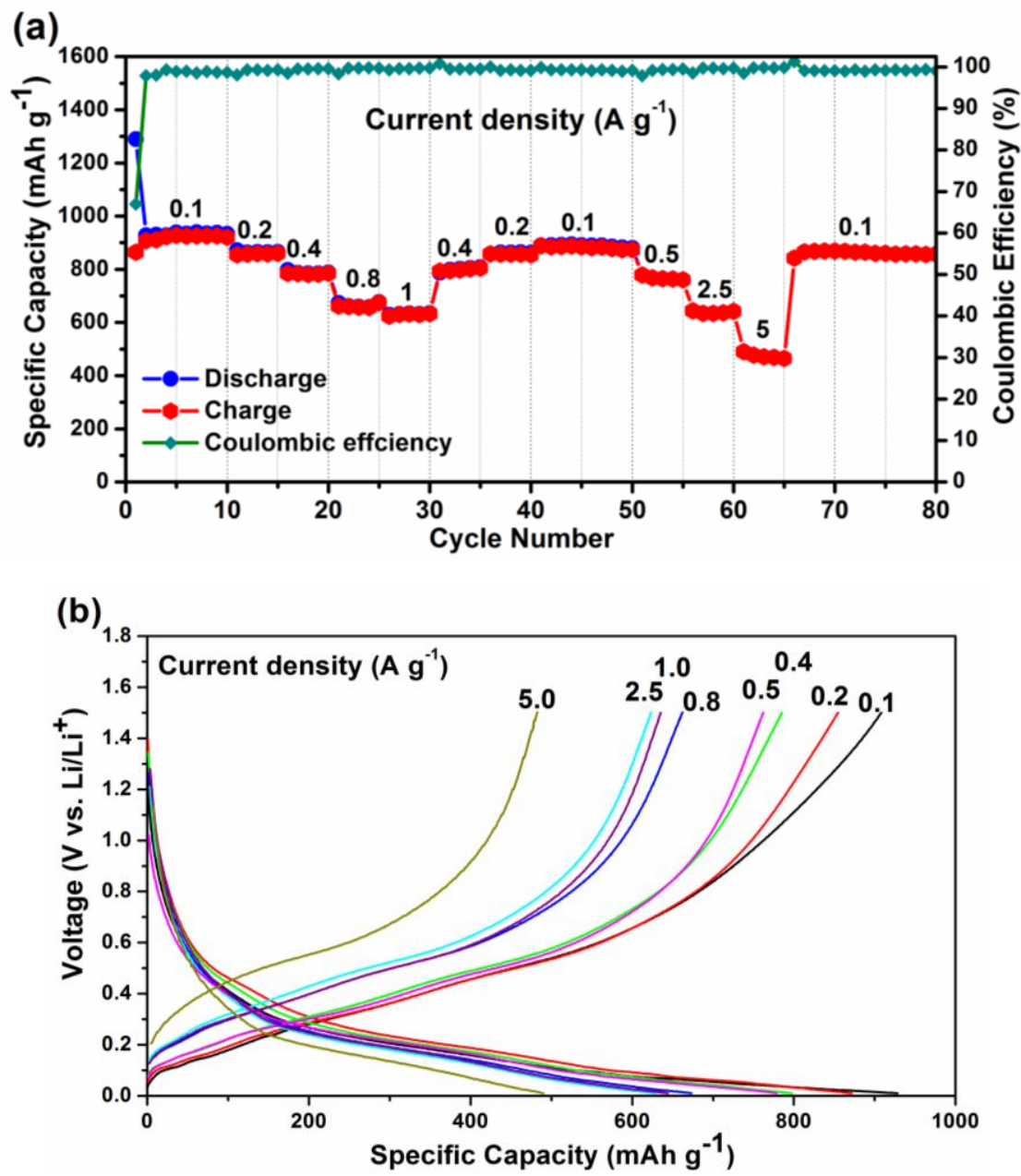

Fig. 6 (a) Cycling performance and (b) discharge/charge profiles of the $\mathrm{Si}_{30} @ \mathrm{C}_{40} / \mathrm{G}_{30}$ composite cycled at various current densities ranging from 0.1 to $5 \mathrm{Ag}^{-1}$.

Because of the good structural stability and superior electrochemical performance of the $\mathrm{Si}_{30} @ \mathrm{C}_{40} / \mathrm{G}_{30}$ composite, the rate capability was further systematically investigated. The anode exhibited stable capacity without any significant decay while the current density was varied between 0.1 and $5.0 \mathrm{~A} \mathrm{~g}^{-1}$ (Fig.6 a). Even at a current density as high as $5.0 \mathrm{~A} \mathrm{~g}^{-1}$, the anode still delivers an average reversible capacity of $475 \mathrm{mAh} \mathrm{g}^{-1}$ after 60 cycles, which is still higher than the theoretical capacity of graphite. Notably, after high rate charge/discharge cycling at $5.0 \mathrm{~A} \mathrm{~g}^{-1}$, the specific capacity is restored to 860 
$\mathrm{mAh} \mathrm{g}^{-1}$ when the current density returns to $0.1 \mathrm{~A} \mathrm{~g}^{-1}$, suggesting very good rate performance. The corresponding Coulombic efficiency of the $\mathrm{Si}_{30} @ \mathrm{C}_{40} / \mathrm{G}_{30}$ composite reaches over $98 \%$ after four cycles and remain stable at varying current density, which is a meaningful result for practical applications. Furthermore, the discharge/charge profiles are similar in shape at different current densities (Fig.6 b), revealing that the nanosized $\mathrm{Si}$ were active toward $\mathrm{Li}^{+}$in the composite at both low and high current rates. This excellent rate capability stems from the good electrical and $\mathrm{Li}^{+}$conductivity of the carbon coating and the network of graphene sheets.

\section{Conclusion}

In summary, a silicon@carbon/graphene sheets $(\mathrm{Si} @ \mathrm{C} / \mathrm{G})$ composite consisting of carbon-coated Si nanoparticles uniformly dispersed into a matrix of graphene sheets has been successfully produced by a combination of high-energy wet ball-milling and pyrolysis. The in-situ carbon coating strengthens the connection between the $\mathrm{Si}$ nanoparticles and graphene sheets matrix, which thereby provides high electrical conductivity to the entire electrode, resulting in high capacity, good cycling stability and superior rate capability. We have also demonstrated that further adjustment of the relative mass ratio of $\mathrm{Si}$, carbon, and graphene sheets could improve the overall composite electrode performance. The as-achieved $\mathrm{Si}_{30} @ \mathrm{C}_{40} / \mathrm{G}_{30}$ composite exhibited remarkably improved cycling stability of a considerable Li-storage capacity of 645 $\mathrm{mAh} \mathrm{g}^{-1}$ remained even after 300 cycles. Most importantly, the reversible capacity decay in these 300 cycles is as small as $0.06 \%$ per cycle. Besides, the synthetic method 
we have described here is simple, low-cost and pollution-free, and has the potential to be easily implemented for large-scale production and also to be extended to other attractive lithium storage metals and alloys.

\section{Acknowledgements}

This work was supported by the National Science Foundation of China (Projects 51201065 and 51231003), by the Guangdong National Science Foundation (Project S2013010012487). Wei Sun would like to thank Prof. Teunis van Ree for the fruitful discussion.

\section{References}

[1] B. Scrosati, J. Garche, J. Power Sources 195 (2010) 2419-2430.

[2] P.G. Bruce, B. Scrosati, J.M. Tarascon, Angew. Chem. 47 (2008) 2930-2946.

[3] C. Liu, F. Li, L.-P. Ma, H.-M. Cheng, Adv. Mater. 22 (2010) E28-E62.

[4] W.-J. Zhang, J. Power Sources 196 (2011) 13-24.

[5] H. Wu, Y. Cui, Nano Today 7 (2012) 414-429.

[6] J.R. Szczech, S. Jin, Energy \& Environ. Sci. 4 (2011) 56-72.

[7] W. Sun, R. Hu, H. Liu, H. Zhang, J. Liu, L. Yang, H. Wang, M. Zhu, Electrochim. Acta 191 (2016) 462-472.

[8] T. Cetinkaya, M.O. Guler, H. Akbulut, Microelectron. Eng 108 (2013) 169-176.

[9] U. Kasavajjula, C. Wang, A.J. Appleby, J. Power Sources, 163 (2007) 1003-1039.

[10] W.J. Lee, T.H. Hwang, J.O. Hwang, H.W. Kim, J. Lim, H.Y. Jeong, J. Shim, T.H. Han, J.Y. Kim, J.W. Choi, S.O. Kim, Energy \& Environ. Sci., 7 (2014) 621-626. 
[11] J. Shin, K. Park, W.-H. Ryu, J.-W. Jung, I.-D. Kim, Nanoscale 6 (2014) 1271812726.

[12] X. Huang, Z. Zeng, Z. Fan, J. Liu, H. Zhang, Adv. Mater. 24 (2012) 5979-6004.

[13] S. Yang, X. Feng, S. Ivanovici, K. Mullen, Angew. Chem. 49 (2010) 8408-8411.

[14] K.S. Novoselov, V.I. Fal'ko, L. Colombo, P.R. Gellert, M.G. Schwab, K. Kim, Nature 490 (2012) 192-200.

[15] W. Sun, R. Hu, H. Liu, M. Zeng, L. Yang, H. Wang, M. Zhu, J. Power Sources, 268 (2014) 610-618.

[16] R. Hu, W. Sun, Y. Chen, M. Zeng, M. Zhu, J. Mater. Chem. A 2 (2014) 9118.

[17] H. Xiang, K. Zhang, G. Ji, J.Y. Lee, C. Zou, X. Chen, J. Wu, Carbon 49 (2011) $1787-1796$.

[18] I.-Y. Jeon, Y.-R. Shin, G.-J. Sohn, H.-J. Choi, S.-Y. Bae, J. Mahmood, S.-M. Jung, J.-M. Seo, M.-J. Kim, D.W. Chang, Proc. Natl. Acad. Sci. 109 (2012) 5588-5593.

[19] K.S. Novoselov, A.K. Geim, S. Morozov, D. Jiang, Y. Zhang, S. Dubonos, I. Grigorieva, A. Firsov, Science 306 (2004) 666-669.

[20] S. Bae, H. Kim, Y. Lee, X. Xu, J.-S. Park, Y. Zheng, J. Balakrishnan, T. Lei, H.R. Kim, Y.I. Song, Nat. Nanotechnol. 5 (2010) 574-578.

[21] X. Yuan, H. Xin, X. Qin, X. Li, Y. Liu, H. Guo, Electrochim. Acta 155 (2015) 251256.

[22] H. Tang, Y.J. Zhang, Q.Q. Xiong, J.D. Cheng, Q. Zhang, X.L. Wang, C.D. Gu, J.P. Tu, Electrochim. Acta 156 (2015) 86-93.

[23] C. Fang, Y. Deng, Y. Xie, J. Su, G. Chen, J. Phy. Chem. C 119 (2015) 1720-1728. 
[24] H. Wu, W. Zhao, H. Hu, G. Chen, J. Mater. Chem. 21 (2011) 8626-8632.

[25] M.J. McAllister, J.-L. Li, D.H. Adamson, H.C. Schniepp, A.A. Abdala, J. Liu, M. Herrera-Alonso, D.L. Milius, R. Car, R.K. Prud'homme, Chem. Mater. 19 (2007) 43964404.

[26] K. Feng, W. Ahn, G. Lui, H.W. Park, A.G. Kashkooli, G. Jiang, X. Wang, X. Xiao, Z. Chen, Nano Energy 19 (2016) 187-197.

[27] H. Li, C. Lu, B. Zhang, Electrochim. Acta 120 (2014) 96-101.

[28] X. Chen, Y. Huang, J. Chen, X. Zhang, C. Li, H. Huang, Ceram. Int. 41 (2015) 8533-8540.

[29] M. Zhou, T. Cai, F. Pu, H. Chen, Z. Wang, H. Zhang, S. Guan, ACS Appl. Mater. \& Interfaces 5 (2013) 3449-3455.

[30] W. Sun, R. Hu, H. Zhang, Y. Wang, L. Yang, J. Liu, M. Zhu, Electrochim. Acta 187 (2016) 1-10.

[31] X. Hou, M. Zhang, J. Wang, S. Hu, X. Liu, Z. Shao, J. Alloys Compd 639 (2015) $27-35$.

[32] S. Li, W. Yan, W.-x. Zhang, Green Chem. 11 (2009) 1618-1626.

[33] Z. Guo, E. Milin, J. Wang, J. Chen, H. Liu, J. Electrochem. Soc. 152 (2005) A2211A2216.

[34] T. Liu, L. Zhao, J. Zhu, B. Wang, C. Guo, D. Wang, J. Mater. Chem. A, 2 (2014) 2822.

[35] C. Ma, C. Ma, J. Wang, H. Wang, J. Shi, Y. Song, Q. Guo, L. Liu, Carbon 72 (2014) $38-46$. 
[36] A. Ferrari, J. Robertson, Phys. Rev. B 64 (2001) 075414.

[37] A. Ferrari, J. Robertson, Phys. Rev. B 61 (2000) 14095.

[38] T. Xing, L.H. Li, L. Hou, X. Hu, S. Zhou, R. Peter, M. Petravic, Y. Chen, Carbon (2013).

[39] S.-L. Chou, J.-Z. Wang, M. Choucair, H.-K. Liu, J.A. Stride, S.-X. Dou, Electrochem. Commun. 12 (2010) 303-306.

[40] J. Wu, X. Qin, H. Zhang, Y.-B. He, B. Li, L. Ke, W. Lv, H. Du, Q.-H. Yang, F. Kang, Carbon 84 (2015) 434-443.

[41] N. Lin, J. Zhou, L. Wang, Y. Zhu, Y. Qian, ACS Appl. Mater. \& Interfaces 7 (2015) 409-414. 


\section{Table 1}

Electrochemical properties of the $\mathrm{Si} @ \mathrm{C} / \mathrm{G}$ composites with different compositions as well as the pristine $\mathrm{Si}, \mathrm{Si} @ \mathrm{C}$ and $\mathrm{Si} / \mathrm{G}$ samples. (The capacity retention after different cycles was calculated upon initial reversible capacity.)

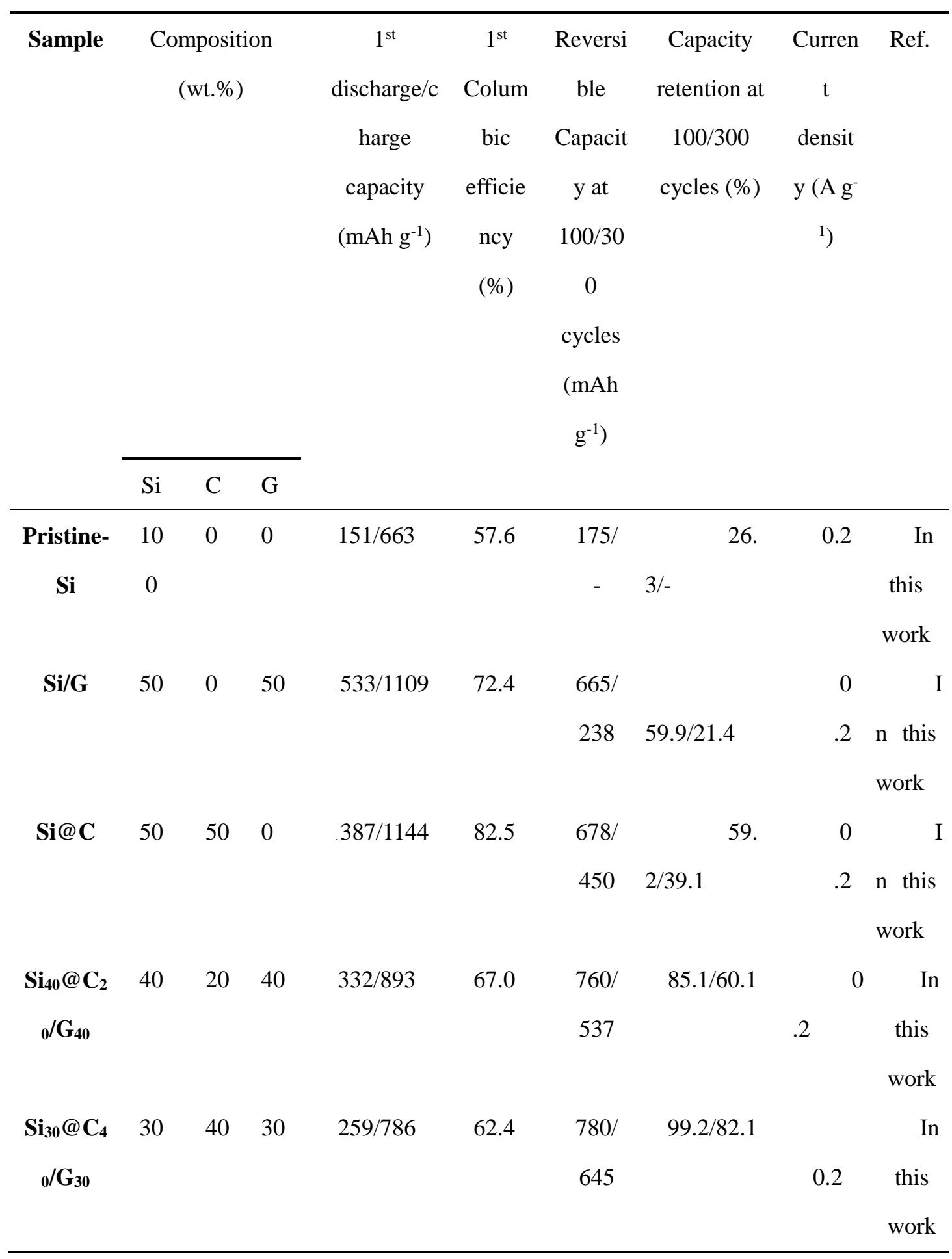




\begin{tabular}{|c|c|c|c|c|c|c|c|c|c|}
\hline $\mathrm{Si}_{20} @ \mathrm{C}_{6}$ & 20 & 60 & 20 & $040 / 531$ & 51.1 & $496 /$ & $93.4 / 73.6$ & & In \\
\hline \multirow[t]{2}{*}{${ }_{0} / \mathbf{G}_{20}$} & & & & & & 391 & & 0.2 & this \\
\hline & & & & & & & & & work \\
\hline \multirow[t]{4}{*}{$\mathrm{Si} / \mathbf{r G O}$} & 32. & 0 & 67 & $404 / 2250$ & 66.0 & 1261 & $56.0\left(70^{\text {th }}\right.$ & & [22] \\
\hline & 8 & & .2 & & & $\left(70^{\text {th }}\right.$ & cycle) & 0.05 & \\
\hline & & & & & & cycl & & & \\
\hline & & & & & & e) & & & \\
\hline \multirow[t]{2}{*}{ G-Si-C } & 63. & 25. & 10 & $319 / 1328$ & 57.3 & $902 /$ & $67.9 /-$ & & [29] \\
\hline & 9 & 2 & .9 & & & - & & 0.3 & \\
\hline \multirow[t]{2}{*}{ Si-C/G } & 30. & - & - & $550 / 1020$ & & $765 /$ & $75.0 /-$ & 0 & [40] \\
\hline & 7 & & & & 62.0 & - & & .2 & \\
\hline \multirow[t]{4}{*}{$\mathbf{S i} @ \mathbf{C} / \mathbf{G}$} & 80. & 16. & 2. & )80/1741 & 83.7 & 1410 & 67/-(upon & & [27] \\
\hline & 88 & 98 & 14 & & & I- & charge & 0.5 & \\
\hline & & & & & & & capacity form & & \\
\hline & & & & & & & $9^{\text {th }}$ cycle) & & \\
\hline \multirow{5}{*}{$\begin{array}{c}\mathbf{S i} @ \mathbf{C} / \mathbf{r} \\
\text { GO }\end{array}$} & 70 & - & - & $J 11 / 1630$ & 81.1 & 1121 & $68.7\left(230^{\text {th }}\right.$ & & [41] \\
\hline & & & & & & $(230$ & cycle) & 0.3 & \\
\hline & & & & & & th & & & \\
\hline & & & & & & cycl & & & \\
\hline & & & & & & e) & & & \\
\hline
\end{tabular}




\section{Graphic Abstract:}

Binding of carbon coated nano-silicon in graphene sheets by wet ballmilling and pyrolysis as high performance anodes for Lithium-ion batteries

Wei Sun, Renzong Hu, Miao Zhang, Jiangwen Liu, and Min Zhu*

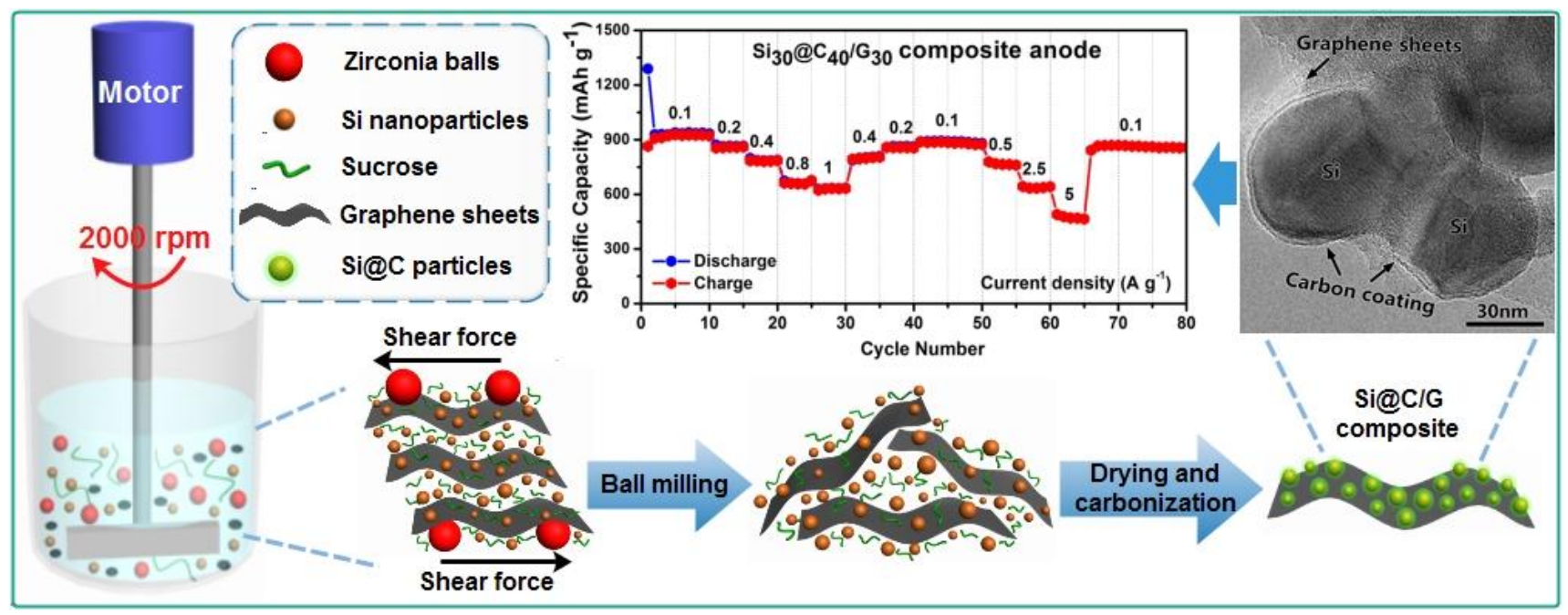

